\title{
Psoriatic arthritis: epidemiology, clinical features, course, and outcome
}

\author{
D D Gladman, C Antoni, P Mease, D O Clegg, P Nash
}

Ann Rheum Dis 2005;64(Suppl II):ii14-ii17. doi: 10.1136/ard.2004.032482

Psoriatic arthritis ( $\mathrm{Ps} A$ ) has been defined as a unique inflammatory arthritis associated with psoriasis. Its exact prevalence is unknown, but estimates vary from $0.3 \%$ to $1 \%$ of the population. The clinical features described initially are recognised by most experienced clinicians, although they are most distinct in early disease. Initially, PsA typically presents as an oligoarticular and mild disease. However, with time PsA becomes polyarticular, and it is a severe disease in at least $20 \%$ of patients. Patients with PsA who present with polyarticular disease are at risk for disease progression. In addition to progression of clinical and radiological damage, health related quality of life is reduced among patients with PsA. It important to note that patients included in recent drug trials resemble patients followed prospectively in a clinic.

$\mathrm{P}$ oriatic arthritis (PsA) has been defined as an inflammatory arthritis, usually seronegative, associated with psoriasis. ${ }^{1}$ It emerged as a clinical entity separate from rheumatoid arthritis (RA) following the discovery of the rheumatoid factor in 1948 and the observations of the late Professor Verna Wright of Leeds, UK. Even though the identity of a specific form of arthritis associated with psoriasis has been questioned, ${ }^{2}$ epidemiological evidence strongly supports the existence of PsA. ${ }^{3}$

\section{EPIDEMIOLOGICAL EVIDENCE FOR PsA}

The prevalence of psoriasis among patients with arthritis in the general population is $2-3 \%$, but among patients with arthritis it is $7 \%$. Inflammatory arthritis occurs in $2-3 \%$ of the general population, but among patients with psoriasis the prevalence of inflammatory arthritis varies from $6 \%$ to $42 \%$. Thus, there is a distinct increase in the prevalence of inflammatory arthritis with varied patterns of presentation that are associated with psoriasis. The genetic epidemiology of PsA also supports its unique status. PsA has been associated with human leucocyte antigen (HLA) class 1 alleles as opposed to the class 2 alleles associated with RA. ${ }^{4}$

The exact prevalence of PsA is unknown and its estimation has been difficult, partly due to the lack of a widely accepted classification or diagnostic criteria, and partly due to the fact that even experts may fail to make the correct diagnosis. ${ }^{5} 6$ Estimated prevalence rates vary from $0.04 \%$ in the Faroe Islands to $0.1 \%$ in a study from the Mayo Clinic. ${ }^{3}$ The reported incidence of PsA has varied from 3.4 to 8 per $100000 .^{7-9}$ It may very well be that these are underestimates. As described above, althought the prevalence of psoriasis has been estimated between $2 \%$ and $3 \%$, the estimated prevalence of inflammatory arthritis among patients with psoriasis has varied widely from $6 \%$ to $42 \%$. A recent study from Sweden suggests that PsA occurs in $30 \%$ of patients with psoriasis. ${ }^{10}$ Similarly a study of patients attending a psoriasis clinic identified $31 \%$ as having PsA. ${ }^{11}$ If this prevalence is correct, the prevalence of PsA in the general population should be close to $1 \%$. Once the ClASsification of Psoriatic ARthritis (CASPAR) group arrives at a valid set of diagnostic/ classification criteria, a proper prospective epidemiological study can be performed to determine accurately the prevalence of the disease.

\section{CLINICAL FEATURES OF PsA}

Wright identified five clinical patterns among patients with PsA: distal predominant pattern, oligoarticular asymmetrical, polyarticular RA-like, spondylitis, and arthritis mutilans. The exact frequency of the patterns has varied even in Wright's publications. Moll and Wright's seminal paper identified the majority of PsA patients as having oligoarthritis. ${ }^{1}$ Over the past four decades, a number of studies have been published confirming the varied clinical patterns seen in PsA. ${ }^{12}$ The frequency of distribution of the patterns has varied, partly because different definitions might have been used by individual investigators, and partly due to the fact that the patterns likely change over time, such that with longer duration of PsA, patients tend to develop the polyarticular pattern $^{13}$ (table 1). Thus these patterns are likely more relevant at disease onset and may not be helpful in the classification of PsA when the disease is already established.

Several clinical features help distinguish PsA from RA. Although RA is more common in women, PsA occurs just as frequently in both sexes. The specific clinical features include the common involvement of distal joints in PsA. The joint distribution tends to occur in a ray pattern in PsA so that all the joints of a single digit are more likely to get affected than the same joints on both sides, which is typical of RA. This may explain the tendency to asymmetry that occurs even in the polyarticular disease in PsA. The degree of erythema over affected joints, the presence of spinal involvement, the presence of enthesitis, and lower level of tenderness are also typical features of PsA. ${ }^{24}$ Although the level of tenderness detected by dolorimetry is clearly different between patients with PsA and those with RA, the Health Assessment Questionnaire (HAQ) scores identified in clinical trials are similar. It is possible that the presence of enthesitis makes a difference.

Extra-articular manifestations of PsA are also different from those of RA. In particular, rheumatoid nodules are absent. Rheumatoid factor, which is detected in more than $80 \%$ of patients with RA may be detected in about $13 \%$ of patients with PsA. The deformities that result from PsA lead to shortening of digits because of severe joint or bone lysis, with the most severe form being the telescoping of digits. Bony fusion of joints may also occur in PsA. These changes are seen in radiographs as the classic pencil in cup and ankylosis, respectively. ${ }^{25}$ PsA is associated with periosteal

Abbreviations: $\mathrm{Ps} A$, psoriatic arthritis; $R A$, rheumatoid arthritis 
Table 1 A comparison of the published series of patients with PsA

\begin{tabular}{|c|c|c|c|c|c|c|c|c|c|c|}
\hline Feature & $\begin{array}{l}\text { Roberts ef al } \\
(1976)^{14}\end{array}$ & $\begin{array}{l}\text { Kammer ef al } \\
(1979)^{15}\end{array}$ & $\begin{array}{l}\text { Scarpa et al } \\
(1984)^{16}\end{array}$ & $\begin{array}{l}\text { Gladman et al } \\
(1987)^{17}\end{array}$ & $\begin{array}{l}\text { Helliwell ef al } \\
(1991)^{18}\end{array}$ & $\begin{array}{l}\text { Torre-Alonso et al } \\
(1991)^{19}\end{array}$ & $\begin{array}{l}\text { Veale et al } \\
(1994)^{20}\end{array}$ & $\begin{array}{l}\text { Jones et al } \\
(1994)^{21}\end{array}$ & $\begin{array}{l}\text { Trabace et al } \\
(1994)^{22}\end{array}$ & $\begin{array}{l}\text { Marsal et al } \\
(1999)^{23}\end{array}$ \\
\hline No of patients & 168 & 100 & 62 & 220 & 50 & 180 & 100 & 100 & 58 & 73 \\
\hline Male/female & $67 / 101$ & $47 / 53$ & $29 / 33$ & $104 / 116$ & $32 / 18$ & $99 / 81$ & $59 / 41$ & $43 / 57$ & $35 / 33$ & $37 / 36$ \\
\hline Age of onset (years) & $36-45$ & $33-45$ & $40-60$ & 37 & 39 & 39 & 34 & 37.6 & 42 & 42 \\
\hline Oligoarthritis (\%) & 53 & 54 & 16 & 14 & 14 & 37 & 43 & 26 & 50 & 7 \\
\hline Polyarthritis (\%) & 54 & 25 & 39 & 40 & 78 & 35 & 33 & 63 & 40 & 88 \\
\hline Distal (\%) & 17 & $?$ & 7.5 & 12 & 0 & 0 & 16 & 1 & $?$ & 4 \\
\hline Back (\%) & 5 & 21 & 21 & 2 & 6 & 7 & 4 & 6 & $?$ & 1 \\
\hline Mutilans (\%) & 5 & $?$ & 2.3 & 16 & 2 & 4 & 2 & 4 & $?$ & 14 \\
\hline Sacroiliitis (\%) & $?$ & $?$ & 16 & 27 & 36 & 20 & 15 & 6 & 43 & 14 \\
\hline Joints before skin (\%) & 16 & 30 & $?$ & 17 & $?$ & 15 & $?$ & 18 & $?$ & $?$ \\
\hline
\end{tabular}

reaction, enthesitis, and spinal involvement. A typical clinical feature of PsA is dactylitis, inflammation of an entire digit, likely from inflammation affecting both the joints and the tendons. Magnetic resonance imaging (MRI) scans have demonstrated that both tenosynovitis and synovitis contribute to the clinical picture of dactylitis. ${ }^{26}$

PsA is classified with the spondyloarthropathies because of the presence of spondylitis in up to $40 \%$ of patients, the occurrence of extra-articular features common to the spondyloarthropathies (mucous membrane lesions, iritis, urethritis, diarrhoea, aortic root dilatation), and association with HLA-B27. PsA may be distinguished from the other spondyloarthropathies by the presence of peripheral arthritis, asymmetrical distribution of the spinal involvement (both sacroiliac joints and syndesmophytes), lower level of pain, and limitation of movement. ${ }^{24}$

Although by definition, all patients with PsA must have psoriasis, and the arthritis may precede the psoriasis by many years, the common scenario is that psoriasis has its onset $\sim 10$ years before PsA. Nail lesions are very common and help distinguish between patients who have PsA and those who have RA, and between patients with psoriasis who have arthritis and those who do not have arthritis. Nail lesions occur in about $40-45 \%$ of patients with psoriasis uncomplicated by arthritis and about $87 \%$ of patients with PsA. ${ }^{27}$ While psoriasis and RA may coexist with a prevalence of 3:10 000, it appears that the presence of 20 nail pits distinguishes patients with PsA from those with RA and psoriasis. ${ }^{28}$

\section{Clinical features of PsA in observational cohorts and clinical trials}

Since PsA presents in different patterns, how do patients included in longitudinal observational cohorts compare with those included in drug trials? Some of the drug trials have included patients with five or more swollen joints, whereas others have included patients with three or more swollen joints. Table 2 presents a comparison of the clinical features noted among patients followed prospectively in a longitudinal clinic with those reported in recent drug trials. Generally, the ages at onset and presentation are similar and sex distribution and the numbers of tender and swollen joints are similar in the longitudinal cohort and the drug trials.

\section{COURSE OF PsA}

Moll and Wright's description of PsA suggested that the disease was less severe than that seen in RA. ${ }^{1}$ However, over the past two decades it has become clear that PsA is much more aggressive than previously thought. About $20 \%$ of the patients develop a very destructive disabling form of arthritis. Over time there is clinically active arthritis such that by the time patients have been followed for more than 10 years, 55\% have five or more deformed joints. ${ }^{35} \mathrm{~A}$ recent study of early onset PsA showed that within two years of onset, $47 \%$ of patients demonstrated at least one erosion. ${ }^{36}$ This rate is in keeping with previous observations that $67 \%$ of patients seen in PsA clinics had evidence of erosive disease. ${ }^{19}{ }^{35}$ One study identified clinical predictors for progression of clinical

Table 2 Comparison of features from longitudinal clinic data and drug trials of psoriatic arthritis ( $P s A)$

\begin{tabular}{|c|c|c|c|c|c|c|c|}
\hline & \multirow{2}{*}{$\begin{array}{l}\text { PsA } \\
\text { Clinic }^{17 *}\end{array}$} & \multicolumn{6}{|l|}{ Trials } \\
\hline & & Sulfasalazine $^{29}$ & Leflunomide ${ }^{30}$ & Etanercept $2^{31}$ & Etanercept $3^{32}$ & Infliximab $2^{33}$ & Infliximab $3^{34}$ \\
\hline \multicolumn{8}{|l|}{ Demographic features } \\
\hline No of patients & 650 & 221 & 190 & 60 & 205 & 102 & 200 \\
\hline Male/female & $364 / 286$ & $169 / 51$ & $112 / 78$ & $34 / 26$ & $105 / 100$ & $60 / 104$ & NA \\
\hline Duration of psoriasis & 14.6 & & 19.5 & 18 & 19 & NA & NA \\
\hline Duration of arthritis & 7.5 & 12 & 10.5 & 10 & 9 & 16 & 5.4 \\
\hline Age at first visit (years) & 43.5 & 50 & 48 & 45 & 47 & 46 & 47 \\
\hline \multicolumn{8}{|l|}{ Clinical features } \\
\hline No of patients & 650 & 221 & 190 & 60 & 205 & 102 & 200 \\
\hline No of tender joints & 10 & 13 & 19 & 20 & NA & 20 & 23 \\
\hline No of swollen joints & 3 & NA & 12 & 14 & NA & 13 & 12 \\
\hline Spondylitis & $37 \%$ & $74 \%$ & NA & NA & $3 \%$ & NA & $8 \%$ \\
\hline Dactylitis & $34 \%$ & NA & NA & NA & NA & NA & $40 \%$ \\
\hline \multicolumn{8}{|c|}{ Acute phase reactants and health status } \\
\hline No of patients & 349 & 221 & 190 & 60 & 205 & 102 & 200 \\
\hline Mean ESR/CRP & & NA & NA & $18 / 1.3$ & NA & $30 / 6$ & NA \\
\hline $\mathrm{HAQ}$ & 0.68 & NA & 1.1 & NA & 1.1 & 1.1 & 1.1 \\
\hline
\end{tabular}


damage. ${ }^{37}$ Progression was defined by the change in clinical damage state (state 1 reflects no damaged joints; state 2 , one to four damaged joints; state 3, five to nine damaged joints; stage 4, greater than 10 such joints). Predictors for progression included five or more swollen joints and a high medication level at presentation to the clinic, particularly use of steroids. A low sedimentation rate at presentation to clinic was noted to be "protective". ${ }^{37}$ In another study from a different centre, polyarticular onset predicted not only the development of clinical deformities but also erosive disease. ${ }^{38}$

HLA antigens have also been found to be predictive of progression of clinical damage. HLA-B22 was protective; HLA-B27 in the presence of HLA-DR7, HLA-B39, and HLADQw3 in the absence of HLA-DR7, were predictive of subsequent damage. ${ }^{39}$ The authors found at follow up that for each actively inflamed joint (tender and/or swollen), there was a $4 \%$ risk of increased damage at the next visit, which was six months later..$^{40}$ Thus, if a patient had 20 actively inflamed joints (which is what was found in the clinical trials), there was an $80 \%$ chance of progression of damage from the beginning to the end of the trial. Females tend to progress more than males, and current damage is predictive of future damage.

The severity of PsA is reflected not only in the accrual of joint damage but also in increased mortality. Patients with PsA are at an increased risk for death with a standardised mortality ratio of $1.62 .{ }^{41}$ The causes of death are similar to those noted in the general population, with cardiovascular causes being the commonest. The risk for premature death is related to previously active and severe disease, the level of medication, the presence of erosive disease, and a high sedimentation rate at presentation to clinic. ${ }^{42}$ This study was based on a cohort of patients with PsA followed prospectively over close to 20 years. A review of PsA patients identified through an administrative database described the disease as mild, and there were no deaths. ${ }^{43}$

One study showed patients with PsA had similar radiological damage as patients with RA, suggesting that the disease may be just as destructive radiologically. ${ }^{44}$ Another study suggested that the radiological changes are not quite as severe. ${ }^{45}$ It has been reported that there is a group of patients who may achieve remission, defined as no actively inflamed joints for a period of 12 months. ${ }^{46}$ These tend to be men with a lower number of actively inflamed joints at presentation. However, after an average of 2.6 years, $52 \%$ of these patients had flares, and only $6 \%$ sustained a complete prolonged remission on no medications and without evidence of clinical or radiological damage. ${ }^{46}$

\section{HEALTH STATUS IN PsA}

Patients with PsA have reduced quality of life and functional capacity compared with psoriasis patients or healthy controls. ${ }^{47}{ }^{48}$ The use of the original HAQ appears to be sufficient, as it has been found that the addition of features related to spinal or skin did not alter the level of disability noted by patients with PsA. ${ }^{374-51}$ The impact of the disease in patients with PsA appears to be similar to that of patients with RA. Sokoll et a $l^{45}$ demonstrated that the HAQ was similar in these two groups of patients. Husted et al demonstrated that patients with PsA have less vitality than those with RA. ${ }^{50}$ Thus, the severity of the disease has an impact on the functional status and quality of life of patients with PsA. The Medical Outcome Survey Short Form 36 (SF-36) has also been validated in PsA and has shown significant differences between patients with PsA and the general population..$^{52}$ The SF-36 was found to be somewhat better than the HAQ in reflecting changes in disease features over time. ${ }^{14}$ Both the HAQ and the SF-36 have been used in clinical trials and have shown improvement in patients treated with drugs.
Recently a specific quality of life instrument for PsA was developed. ${ }^{53}$ Whether this instrument functions better than the HAQ or SF-36, in terms of identifying issues specific to PsA and sensitivity to change, remains to be determined.

\section{SUMMARY}

PsA may be more common than previously described. In addition, the burden of disease is demonstrated both in terms of progression of clinical and radiological damage, and in terms of quality of life and functional status of these patients. Moreover, patients with PsA are at an increased risk of death, which is related to the severity of their disease.

\section{Authors' affiliations}

D D Gladman, University of Toronto, Toronto Western Research Institute, Psoriatic Arthritis Program, University Health Network, Centre for Prognosis Studies in the Rheumatic Diseases, Toronto Western Hospital, Toronto, Ontario, Canada

C Antoni, Department of Medicine-3, Friedrich-Alexander University, Erlangen-Nuremberg, Germany

P Mease, Seattle Rheumatology Associates; Rheumatology Clinical Research, Swedish Hospital Medical Center; University of Washington School of Medicine, Seattle, WA, USA

D O Clegg, Rheumatology Section, Salt Lake City Veterans Health Care System, University of Utah School of Medicine, Salt Lake City, Utah, USA P Nash, Rheumatology Research Unit, Nambour Hospital, Sunshine Coast; and Department of Medicine, University of Queensland, Queensland, Australia

Correspondence to: Dr D Gladman, Toronto Western Hospital, 399 Bathurst St ECW 5-034B, Toronto, Ontario, M5T 2S8, Canada; dafna. gladman@utoronto.ca

\section{REFERENCES}

1 Wright V, Moll JMH. Psoriatic arthritis. In: Wright V, Moll JMH, eds. Seronegative polyarthritis. Amsterdam: North Holland Publishing Co, 1976:169-223

2 Cats A. Psoriasis and arthritis. Cutis 1990;46:323-9.

3 O'Neill T, Silman AJ. Psoriatic arthritis. Historical background and epidemiology. Baillieres Clin Rheumatol 1994;8:245-61.

4 Rahman P, Elder JT. Genetic epidemiology of psoriasis and psoriatic arthritis. Ann Rheum Dis 2005;64(suppl II):ii37-9.

5 Gladman DD. Psoriatic arthritis. Baillieres Clin Rheumatol 1995;9:319-29.

6 Helliwell PS, Taylor WJ. Classification and diagnostic criteria for psoriatic arthritis. Ann Rheum Dis 2005;64(suppl II):ii3-8.

7 Bruce IN. Psoriatic arthritis: clinical features. In: Hochberg MC, Silman JS, Smolen ME, Weinblatt M, Weisman M, eds. Rheumatology, 3rd edn. Philadelphia: Mosby, 2003:1241-52.

8 Savolainen E, Kaipiainen-Seppanen O, Kroger L, Luosujarvi R. Total incidence and distribution of inflammatory joint diseases in a defined population: results from the Kuopio 2000 arthritis survey. J Rheumatol 2003;30:2460-8.

9 Soderlin MK, Borjesson O, Kautiainen H, Skogh T, Leirisalo-Repo M. Annual incidence of inflammatory joint diseases in a population based study in southern Sweden. Ann Rheum Dis 2002:61:911-15.

10 Zachariae H. Prevalence of joint disease in patients with psoriasis: implications for therapy. Am J Clin Dermatol 2003;4:441-7.

11 Brockbank JE, Schentag C, Rosen C, Gladman DD. Psoriatic arthritis (PsA) is common among patients with psoriasis and family medical clinic attendees [abstract]. Arthritis Rheum 2001;44(suppl 9):S94.

12 Gladman DD, Rahman P. Psoriatic arthritis. In: Ruddy S, Harris ED, Sledge CB, Budd RC, Sarjent JS, eds. In: Kelly's Textbook of Rheumatology, 6th edn. Philadelphia: WB Saunders Co, 2001:1071-9.

13 McHugh NJ, Balachrishnan C, Jones SM. Progression of peripheral joint disease in psoriatic arthritis: a 5-yr prospective study. Rheumatology (Oxford) 2003;42:778-83

14 Roberts ME, Wright V, Hill AG, Mehra AC. Psoriatic arthritis. Follow-up study. Ann Rheum Dis 1976;35:206-12.

15 Kammer GM, Soter NA, Gibson DJ, Schur PH. Psoriatic arthritis: a clinical, immunologic and HLA study of 100 patients. Semin Arthritis Rheum 1979;9:75-97.

16 Scarpa R, Oriente P, Pucino A, Torella M, Vignone L, Riccio A, et al. Psoriatic arthritis in psoriatic patients. Br J Rheumatol 1984;23:246-50.

17 Gladman DD, Shuckett R, Russell ML, Thorne JC, Schachter RK. Psoriatic arthritis (PSA) - an analysis of 220 patients. Q J Med 1987;62:127-41.

18 Helliwell P, Marchesoni A, Peters M, Barker M, Wright V. A re-evaluation of the osteoarticular manifestations of psoriasis. Br J Rheumatol 1991;30:339-45.

19 Torre-Alonso JC, Rodriguez Perez A, Arribas Castrillo JM, Ballina Garcia J, Riestra Noriega JL, Lopez Larrea C. Psoriatic arthritis (PA): a clinical, immunological and radiological study. Br J Rheumatol 1991;30:245-50. 
20 Veale D, Rogers S, Fitzgerald $O$. Classification of clinical subsets in psoriatic arthritis. Br J Rheumatol 1994;33:133-8.

21 Jones SM, Armas JB, Cohen MG, Lovell CR, Evison G, McHugh NJ. Psoriatic arthritis: outcome of disease subsets and relationship of joint disease to nail and skin disease. Br J Rheumatol 1994;33:834-9.

22 Trabace S, Cappellacci S, Ciccarone P, Liaskos S, Polito R, Zorzin L. Psoriatic arthritis: a clinical, radiological and genetic study of 58 Italian patients. Acta Derm Venereol Suppl (Stockh) 1994;186:69-70.

23 Marsal S, Armadans-Gil L, Martinez M, Gallardo D, Ribera A, Lience E. Clinical, radiographic and HLA associations as markers for different patterns of psoriatic arthritis. Rheumatology (Oxford) 1999;38:332-7.

24 Gladman DD. Clinical aspects of the spondyloarthropathies. Am J Med Sci 1998;316:234-8.

25 Ory PA. Radiography in the assessment of musculoskeletal conditions. Best Pract Res Clin Rheumatol 2003;17:495-512.

26 Olivieri I, Barozzi L, Pierro A, De Matteis M, Padula A, Pavlica P. Toe dactylitis in patients with spondyloarthropathy: assessment by magnetic resonance imaging. J Rheumatol 1997;24:926-30.

27 Gladman DD, Anhorn KA, Schachter RK, Mervart H. HLA antigens in psoriatic arthritis. J Rheumatol 1986;13:586-92.

28 Eastmond CJ, Wright V. The nail dystrophy of psoriatic arthritis. Ann Rheum Dis 1979;38:226-8

29 Clegg DO, Reda DJ, Mejias E, Cannon GW, Weisman MH, Taylor T, et al. Comparison of sulfasalazine and placebo in the treatment of psoriatic arthritis. A Department of Veterans Affairs Cooperative Study. Arthritis Rheum 1996;39:2013-20.

30 Kaltwasser JP, Nash P, Gladman D, Rosen CF, Behrens F, Jones P, et al. Efficacy and safety of leflunomide in the treatment of psoriatic arthritis and psoriasis: a multinational, double-blind, randomized, placebo-controlled clinical trial. Arthritis Rheum 2004;50:1939-50.

31 Mease PJ, Goffe BS, Metz J, VanderStoep A, Finck B, Burge DJ. Etanercept in the treatment of psoriatic arthritis and psoriasis: a randomised trial. Lancet 2000;356:385-90.

32 Mease PJ, Kivitz AJ, Burch FX, Siegel EL, Cohen SB, Ory P, et al. Etanercept treatment of psoriatic arthritis: safety, efficacy and effect on disease progession. Arthritis Rheum 2004;50:2264-72.

33 Antoni C, Kavanaugh A, Kirkham B, Burmester Q, Weism M, Keystone E, et al. The infliximab multinational psoriatic arthritis controlled trial (IMPACT). Arthritis Rheum 2002;46:S381.

34 Kavanaugh A, Krueger GG, DeVlam K, Birbara C, Beutler A, Guzzo C, et al Infliximab improves arthritis and psoriasis in patients with active polyarticular psoriatic arthritis: Results of the IMPACT 2 trial. Ann Rheum Dis 2004;63(suppl 1):402

35 Gladman DD. The natural history of psoriatic arthritis. In: Wright V, Helliwell PS, eds. Psoriatic arthritis in Baillière's Clinical Rheumatology. International Practice and Research. London: Baillière Tindall, 1994:379-94.

36 Kane D, Stafford L, Bresnihan B, FitzGerald O. A prospective, clinical and radiological study of early psoriatic arthritis: an early synovitis clinic experience Rheumatology (Oxford) 2003;42:1460-8.
37 Gladman DD, Farewell VT, Nadeau C. Clinical indicators of progression in psoriatic arthritis: multivariate relative risk model. J Rheumatol 1995;22:675-9.

38 Queiro-Silva R, Torre-Alonso JC, Tinture-Eguren T, Lopez-Lagunas I. A polyarticular onset predicts erosive and deforming disease in psoriatic arthritis. Ann Rheum Dis 2003;62:68-70.

39 Gladman DD, Farewell VT, Kopciuk K, Cook RJ. HLA antigens and progression in psoriatic arthritis. J Rheumatol 1998;25:730-3.

40 Gladman DD, Farewell VT. Progression in psoriatic arthritis: Role of time varying clinical indicators. J Rheumatol 1999;26:2409-13.

41 Wong K, Gladman DD, Husted J, Long JA, Farewell VT. Mortality studies in psoriatic arthritis: results from a single outpatient clinic. I. Causes and risk of death. Arthritis Rheum 1997;40:1868-72.

42 Gladman DD, Farewell VT, Wong K, Husted J. Mortality studies in psoriatic arthritis: Results from a single center. II. Prognostic indicators for death. Arthritis Rheum 1998:41:1103-10.

43 Shbeeb M, Uramoto KM, Gibson LE, O'Fallon WM, Gabriel SE. The epidemiology of psoriatic arthritis in Olmsted County, Minnesota, USA, 1982-1991. J Rheumatol 2000;27:1247-50.

44 Rahman P, Nguyen E, Cheung C, Schentag CT, Gladman DD. Comparison of radiological severity in psoriatic arthritis and rheumatoid arthritis. J Rheumatol $2001 ; 28: 1041-4$.

45 Sokoll KB, Helliwell PS. Comparison of disability and quality of life in rheumatoid and psoriatic arthritis. J Rheumatol 2001;28:1842-6.

46 Gladman DD, Hing EN, Schentag CT, Cook RJ. Remission in psoriatic arthritis. J Rheumatol 2001;28:1045-8.

47 Husted JA, Gladman DD, Farewell VT, Long JA, Cook RJ. Validating the SF36 health survey questionnaire in patients with psoriatic arthritis. J Rheumatol 1997:24:511-17.

48 Zachariae H, Zachariae R, Blomqvist K, Davidsson S, Molin L, Mork C, et al. Quality of life and prevalence of arthritis reported by 5795 members of the Nordic Psoriasis Associations. Data from the Nordic Quality of Life Study. Acta Derm Venereol 2002;82:108-13.

49 Husted JA, Gladman DD, Farewell VT, Cook RJ. Health-related quality of life of patients with psoriatic arthritis: a comparison with patients with rheumatoid arthritis. Arthritis Rheum 2001;45:151-8.

50 Husted JA, Gladman DD, Cook RJ, Farewell VT. Responsiveness of health status instruments to changes in articular status and perceived health in patients with psoriatic arthritis. J Rheumatol 1998;25:2146-55.

51 Husted J, Gladman DD, Long J, Farewell VT. A modified version of the Health Assessment Questionnaire (HAQ) for psoriatic arthritis. Clin Exp Rheumatol 1995; 13:439-44.

52 McKenna SP, Doward LC, Whalley D, Tennant A, Emery P, Veale DJ. Development of the PsAQoL: a quality of life instrument specific to psoriatic arthritis. Ann Rheum Dis 2004;63:162-9.

53 Kammer GM, Soter NA, Gibson Blackmore M, Gladman DD, Husted J, Long J, et al. Measuring health status in psoriatic arthritis: The Health Assessment Questionnaire and its modification. J Rheumatol 1995;22:886-93. 